\title{
Guías para la vacunación de perros (caninos) y gatos (felinos) en Perú
}

\author{
Vaccination guidelines for dogs (canine) and cats (feline) in Peru
}

\author{
Alicia Rubio ${ }^{1}$, Ricardo Martínez Ávila², Héctor Guzmán Iturbe ${ }^{3}$, Fernando Chávez \\ Zapata $^{4}$, Gabriela De la Colina ${ }^{5}$, José Salazar Guevara ${ }^{6}$, Ignacio Antonio Ramírez ${ }^{7}$, \\ Helio Autrán de Morais ${ }^{8}$, Jorge Guerrero ${ }^{8}$
}

\section{Resumen}

El Comité Peruano de COLAVAC ha elaborado la presente guía de vacunación para el médico veterinario peruano con la finalidad de ser utilizada como una herramienta en el diseño de calendarios de vacunación para perros y gatos, con base en análisis de riesgo, presencia de enfermedades endémicas y características de las vacunas actualmente disponibles en el Perú. El documento presenta recomendaciones de calendarios de vacunación con vacunas de uso esencial, así como aquellas de uso opcional. La vacunación es un acto médico, por lo que la decisión final debe ser tomada por el clínico considerando, además de los factores antes mencionados, las características propias de cada paciente incluyendo el riesgo/beneficio de la inmunización. En cada caso, la estrategia de vacunación debe ser comentada al propietario para que este pueda tomar una decisión informada.

Palabras clave: manual; vacunación; perros; gatos; COLAVAC

\section{Abstract}

The Peruvian Committee of COLAVAC has prepared this vaccination guide for the Peruvian veterinarian to be used as a tool in the design of vaccination schedules for dogs

\footnotetext{
${ }^{1}$ Veterinaria Rubio, Lima, Perú

${ }^{2}$ Veterinaria Corpac, Lima, Perú

${ }^{3}$ Veterinaria Las Garzas, Lima, Perú

${ }^{4}$ Veterinaria Berchi, Lima, Perú

${ }^{5}$ INVETSA, Lima, Perú

${ }^{6}$ Asociación de Médicos Veterinarios en Práctica de Pequeños Animales - AMVEPPA, Lima, Perú

${ }^{7}$ Universidad Alas Peruanas, Lima, Perú

${ }^{8}$ Comité Internacional COLAVAC-FIAVAC, Barcelona, España

${ }^{9}$ E-mail: jorgegu1@hotmail.com

Documento elaborado por el Comité Peruano de COLAVAC. Trabajo financiado por FIAVAC
}

Recibido: 28 de agosto de 2018

Aceptado para publicación: 5 de septiembre de 2018 
and cats, based on risk analysis, presence of endemic diseases and characteristics of vaccines currently available in Peru. The document present recommendations for vaccination schedules with essential vaccines as well as those of optional use. Vaccination is a medical act, so the final decision must be made by the clinician considering in addition to the factors mentioned above, the characteristics of each patient including the risk/benefit of immunization. In each case, the vaccination strategy should be discussed with the owner so that the owner can make an informed decision.

Key words: manual; vaccination; dog; cat; COLAVAC

\section{INTRODUCCION}

La práctica médico-veterinaria tiene en las vacunas su herramienta más confiable, eficaz y económica para el ejercicio de la medicina preventiva. Sin embargo, la multitud de opciones que dispone el médico veterinario para su aplicación exige que su uso sea racionalizado en calendarios de vacunación. En la práctica médica en animales de compañía, la vacunación debe estar basada en la necesidad de prevenir infecciones presentes en cada región, en un análisis de riesgo/beneficio y en las características de las vacunas disponibles. La vacunación es una práctica médica que solo debe estar en manos del médico veterinario, donde es el clínico el que toma la decisión final de vacunar, así como del tipo de vacuna a utilizar, tomando en cuenta, además, las características individuales de cada paciente. En cada caso, la estrategia de vacunación debe ser explicada al propietario de la mascota, para que este pueda tomar una decisión informada.

La diversidad de posibilidades y opciones para la vacunación de perros y gatos exige que los médicos veterinarios especializados en animales de compañía mantengan una actualización profesional constante y sepan dar solución a eventuales conflictos con los propietarios de los animales. En este mundo globalizado, a causa del Internet, se diseminan fácilmente informaciones tendenciosas que causan enfrentamientos en los servicios veterinarios. Por ello, y para actualizar a los médicos veterinarios, así como para propor- cionarles algunas bases conceptuales y recomendaciones generales, la Federación Iberoamericana de Asociaciones Veterinarias de Animales de Compañía (FIAVAC) creó el Comité Latinoamericano de Vacunología en Animales de Compañía (COLAVAC) que, en asociación con líderes de la profesión médico-veterinaria asumió esta responsabilidad en el Perú. COLAVAC-Perú elaboró la presente guía de vacunación de perros y gatos como una fuente de consulta para los médicos veterinarios de animales de compañía en el ámbito nacional, sobre el uso de vacunas para el control de enfermedades infecciosas, con el fin de preservar su salud y bienestar. COLAVAC ya ha elaborado y presentado guías de vacunación para mascotas en Argentina, Brasil, España, México y Portugal.

El mercado de salud animal ofrece una gran variedad de vacunas para la prevención de diversas enfermedades de caninos y felinos. De ellas, y según las características del paciente, el médico veterinario puede indicar aquellas vacunas que son esenciales y aquellas consideradas como opcionales. La oferta de vacunas en el Perú es generalmente a base de vacunas a múltiples antígenos. Estas son útiles y de cómoda aplicación, pero dificultan el manejo individual de cada antígeno contenido en las vacunas esenciales para la prevención de enfermedades endémicas en el país, tales como distemper, parvovirosis, hepatitis infecciosa canina y leptospirosis, así como las causadas por el adenovirus canino 2 (AVC-2). Este es un desafío a la necesidad de establecer una revacunación cada 2 o 3 años de aquellas vacunas esenciales con las 
que la mascota fue correctamente inmunizada durante su primer año de vida.

Hay países que vacunan a un alto porcentaje de su población canina y felina, de tal manera que la inmunidad poblacional es fuerte. En otros países como ocurre en el Perú, los niveles de vacunación estimados son muy bajos, de modo que la inmunidad de la población también es baja. No se cuenta con estadísticas exactas ni aproximadas de la población canina existente en el país, y tampoco existen estudios confiables sobre la distribución de las enfermedades infecciosas de perros, cepas virales circulantes, etc.

Es pertinente enfatizar que, el propósito de las guías de vacunación, que a continuación se presentan, es compartir y uniformizar entre los médicos veterinarios del país, los fundamentos de las propiedades antigénicas de las vacunas para inducir respuestas inmunológicas de protección en las mascotas, los cuales están basados en la revisión de literatura científica y técnica, así como de la experiencia clínica selecta. Por tanto, el presente documento constituye una orientación o directiva recomendada para implementar planes de vacunación como una práctica eficaz y ética en perros y gatos. Se debe entender que la decisión final de cómo, cuándo y con qué vacunar queda a elección de cada Médico Veterinario.

\section{Tipos de Vacunas Existentes}

Las vacunas comerciales disponibles en el Perú para aplicación en perros y gatos pueden clasificarse a grandes rasgos en dos categorías: vacunas infecciosas y vacunas no infecciosas.

\section{Vacunas infecciosas (vacunas atenuadas o vivas modificadas)}

Estas vacunas están constituidas por microorganismos vivos que sufren un proceso de atenuación para reducir su virulencia.
La atenuación se genera de forma natural (a través de la adaptación del patógeno a un hospedero diferente), o por manipulaciones en el laboratorio (pasajes sucesivos o adaptación a diferentes temperaturas). Los microorganismos presentes en toda vacuna necesitan infectar a las células del hospedero para producir inmunidad. Estos microorganismos atenuados se replican en el paciente generando una infección leve, sin daños significativos en los tejidos ni signos clínicos, pero induciendo, en cambio, una respuesta inmune.

Dentro de esta categoría se consideran también a las vacunas recombinantes vectorizadas, en las cuales un microorganismo vivo transporta una parte del material genético del patógeno objetivo. Si bien estos microorganismos no se replican en el animal, dan lugar a la síntesis de proteínas antigénicas, estimulando la inmunidad de forma segura al no poder revertir a su forma virulenta. En el Perú se dispone de la fracción vacunal recombinante del distemper canino, que emplea como vector al virus de la viruela del canario para transportar material genético del virus del distemper.

Las vacunas atenuadas generan una inmunidad más efectiva, tanto a través de una respuesta de tipo celular (Th1) como de la generación de linfocitos $\mathrm{T}$ de memoria, por lo cual no requieren de sustancias adyuvantes. Por otro lado, estas vacunas son menos estables, por lo que deben mantenerse estrictamente a temperaturas entre 2 y $8{ }^{\circ} \mathrm{C}$. Asimismo, una vez reconstituidas debe evitarse su exposición a agentes químicos que puedan inactivarlas. Estas vacunas se presentan usualmente en el mercado en forma liofilizada, debiendo usarse en un periodo no mayor a una hora después de su reconstitución.

\section{Vacunas no infecciosas (Vacunas muer- tas 0 inactivadas)}

Las vacunas a germen muerto o inactivado están formadas por microorganismos antigénicamente intactos, pero inactivados por 
Cuadro 1. Tipos de vacunas para perros y gatos comercialmente disponibles en Perú

\begin{tabular}{lll}
\hline Tipo de vacuna & & Patógeno \\
\hline Infecciosas & Virus vivo modificado & Parvovirus canino \\
& $($ VVM) & Virus de distemper canino \\
& & Virus de hepatitis infecciosa canina o \\
& & adenovirus canino 2 (AVC-2) \\
& & Virus de parainfluenza Tipo 2 \\
& Coronavirus canino \\
& & Bordetella bronchiseptica \\
& & Virus de la panleucopenia felina (PVF) \\
& & Virus de rinotraquétis felina (HVF) \\
& & Calicivirus felino \\
& Recombinante vectorizada & Virus de distemper canino (vector: virus de \\
& (Vr) & viruela canario) \\
No infecciosas & Virus muerto (VM) & Coronavirus canino \\
& & Virus rábico \\
& Bacterina (B) & Leptospira sp \\
\hline
\end{tabular}

algún método físico o químico sin que se alteren sus propiedades inmunogénicas. Estas vacunas actúan como antígenos exógenos, induciendo una respuesta de tipo humoral (producción de anticuerpos y generación de linfocitos B de memoria). Los microorganismos presentes en estas vacunas son incapaces de replicarse en el hospedero o inducir signos clínicos de enfermedad. Estas vacunas son también más estables durante su almacenamiento en refrigeración ( 2 a $8^{\circ} \mathrm{C}$ ), debido a que están inactivadas y son incapaces de replicarse. No obstante, por la misma razón requieren de una cantidad adecuada de antígeno para inmunizar al paciente y su inmunogenicidad es menor, debiendo asociarse muchas veces a sustancias adyuvantes para estimular una mejor respuesta.

Los adyuvantes comprenden una variedad de sustancias químicas que estimulan una reacción inflamatoria que determinará una mejor respuesta inmune al antígeno vacunal. Si bien el hecho de que los microorganismos en vacunas muertas no pueden recuperar su virulencia, de allí que se les considere más seguras, los residuos de adyuvantes pueden permanecer en las áreas de vacunación en la mascota y ser responsables de reacciones inflamatorias y de hipersensibilidad. Las vacunas a germen muerto o inactivado estarían más ligadas a reacciones adversas locales o sistémicas en perros, en comparación con las vacunas con gérmenes modificados o atenuados. En gatos, diversos estudios demostraron que la administración de vacunas inactivadas $\mathrm{y}$ formuladas con adyuvantes producen reacciones inflamatorias locales extensas en el lugar de inoculación, las cuales no necesariamente eran visibles a nivel macroscópico, a diferencia de los gatos inoculados con vacunas del mismo componente antigénico sin adyuvante, en los cuales la inflamación local fue significativamente menor. 
Las vacunas a germen muerto o inactivado pueden tener una menor duración de inmunidad en comparación con las vacunas con gérmenes modificados o atenuados. La vacuna de rabia es, sin embargo, una excepción al ser altamente inmunogénica, lo que hace que no sea necesario vacunar una vez al año, siendo esta frecuencia anual obligatoria determinada por la legislación sanitaria peruana vigente.

Los tipos de vacunas para perros y gatos comercialmente disponibles en Perú se presentan en el Cuadro 1.

\section{Vacunaciones en Caninos}

La vacunación canina en el Perú no se encuentra legislada (con excepción de la rabia) por alguna entidad gubernamental o gremial. Tal es así que la vacunación, temerariamente, la puede realizar cualquier persona sin los conocimientos mínimos de medicina veterinaria y, generalmente, sin criterios científicos. Contrariamente, la vacunación solo debería ser realizada por un médico veterinario colegiado y hábil.

Las guías de vacunación elaboradas en Estados Unidos y Europa aportan una excelente orientación y una clarificación acerca de todos los aspectos del proceso de inmunización canina, pero no necesariamente se consideran ideales para la realidad peruana. Así, no existe un consenso adecuado de vacunación entre los colegas peruanos, de tal manera que la vacunación se realiza de acuerdo con el criterio de cada uno, sin consideración del tipo y calidad de la vacuna o de la duración de inmunidad que otorgan, sea por falta de acuerdos, reglamentación o desconocimiento. A pesar de existir guías de vacunación preparadas y actualizadas por la World Small Animal Veterinary Association (WSAVA) y la American Animal Hospital Association (AAHA), todo indica que estas no se aplican en el medio nacional, de allí que cada profesional decide su plan de vacuna- ción a su mejor parecer y experiencia, $\mathrm{y}$ es por ello la necesidad de producir una guía de recomendaciones para esta importante actividad médica.

Es importante recordar que las vacunas consisten en microorganismos o fracciones de ellos que, al ser administradas a un animal inducen respuestas inmunológicas capaces de protegerlo frente al contacto posterior con el agente inicial. La respuesta inmune inducida resulta del desarrollo de células efectoras y células de memoria. Las vacunas deben ser eficaces para inducir protección y seguras para no producir enfermedad en el huésped. La eficacia de una vacuna está relacionada con la capacidad de estimular las células presentadoras de antígeno, seguido por la liberación de las citoquinas apropiadas y la estimulación de los linfocitos $\mathrm{T}$ cooperadores (Th), T citotóxicos (Tc) y B, generando un número adecuado de células de memoria y efectoras específicas para el antígeno inoculado. Esta reacción inmunológica se desarrolla, generalmente, entre 2 y 3 semanas. El antígeno contenido en la vacuna debe permanecer, preferiblemente en lugares específicos del tejido linfoide, lo que permite la estimulación continua de las células del sistema inmune. Idealmente, se espera que la vacuna sea capaz de conferir protección a largo plazo frente a una nueva exposición al agente, logrando una inmunidad de larga duración. La memoria inmunológica permitirá una respuesta inmune más intensa frente a una nueva exposición al patógeno.

\section{Vacunas esenciales}

El Grupo de Guías de Vacunación del WSAVA denomina vacunas esenciales a aquellas que todo perro debería recibir, sin importar sus circunstancias o localización geográfica. En el Perú las vacunas esenciales son:

- Vacuna contra el distemper

- Vacuna contra parvovirus 
Cuadro 2. Rol de vacunación recomendado para perros en el Perú. Vacunas esenciales

\begin{tabular}{lllll}
\hline Vacuna & Tipo $^{1}$ & Edad & $1^{\text {er }}$ refuerzo & Posteriormente \\
\hline Parvovirus & VVM & $\begin{array}{l}8,12 \text { y } 16 \\
\text { semanas }\end{array}$ & $\mathrm{Al}$ año & Cada 3 años \\
Distemper & Vr, VVM & $\begin{array}{l}8,12 \text { y } 16 \\
\text { semanas }\end{array}$ & $\mathrm{Al}$ año & Cada 3 años \\
$\begin{array}{llll}\text { Hepatitis infecciosa } \\
\text { canina (AVC-2) }\end{array}$ & $\mathrm{VVM}$ & $\begin{array}{l}8,12 \text { y } 16 \\
\text { semanas }\end{array}$ & $\mathrm{Al}$ año & Cada 3 años \\
$\begin{array}{l}\text { Leptospirosis } \\
\text { Rabia }\end{array}$ & $\mathrm{B}$ & $\begin{array}{l}12 \text { y } 16 \\
\text { semanas } \\
\text { A partir de } \\
14 \text { semanas }\end{array}$ & $\begin{array}{l}\text { Al año } \\
\text { (obligatoria) }\end{array}$ & $\begin{array}{l}\text { Anualmente } \\
\text { (obligatoria) }\end{array}$ \\
\hline
\end{tabular}

${ }^{1}$ VVM: virus vivo modificado; Vr: virus recombinante; B: bacterina; VM: virus muerto

- Vacuna contra la hepatitis infecciosa canina o adenovirus canino 2 (AVC-2)

- Vacuna contra la leptospirosis

- Vacuna contra la rabia. Esta vacuna debe ser aplicada anualmente por ley en todos los caninos

Las vacunas deben comenzar a administrarse entre las 6 y 9 semanas de vida de los cachorros. Antes de esa edad, ocurre interferencia con los anticuerpos recibidos de la madre, también conocida como inmunidad materna pasiva. Además, antes de las seis semanas, el sistema inmune de los cachorros aún está en proceso de desarrollo.

Es esencial para el cachorro la transferencia pasiva de inmunidad a través de la ingestión de anticuerpos (inmunoglobulinas calostrales) presentes en la leche materna para protegerlos durante el periodo neonatal. No obstante, estos anticuerpos maternales pueden interferir con la capacidad de generar una respuesta inmune endógena por el neonato, generando el fenómeno denominado «ventana de susceptibilidad». Este fenómeno explica que algunos cachorros puedan llegar a infectarse y consecuentemente desarrollar sintomatología clínica, aun estando vacunados.

Los intervalos entre las revacunaciones no deben ser menores de 15 días por las razones explicadas anteriormente. Intervalos menores impiden alcanzar una respuesta inmunológica protectora adecuada. El rol de vacunaciones recomendado para perros en el Perú se muestra en el Cuadro 2.

Todo cachorro que haya recibido sus vacunas siguiendo estas recomendaciones, debe ser revacunado al año de haberse colocado la última dosis y de allí en adelante se vacunarán cada tres años debido a que ha quedado demostrado que los efectos protectores de las mismas incluso superan este periodo.

De manera general se recomienda que todo cachorro mayor de seis semanas y menor de seis meses debe recibir:

- Tres (3) dosis de vacunas contra parvovirus, distemper y hepatitis 
- Dos (2) o tres (3) dosis de vacunas contra Leptospira a partir de las 12 semanas

- Una (1) dosis de vacuna antirrábica a partir de las 12 a 16 semanas (en conjunto con la última dosis de las vacunas anteriores)

Así mismo, todo cachorro de seis meses o mayor que nunca haya sido vacunado debe recibir:

- Dos (2) dosis de vacunas contra parvovirus, distemper, hepatitis

- Dos (2) vacunas contra Leptospira

- Una dosis de vacuna antirrábica en conjunto con la primera dosis de las anteriores

La revacunación contra la rabia canina es anual por ley en el Perú.

Para la vacunación contra leptospirosis se usa una bacterina. Se recomienda iniciar la vacunación a las 12 semanas. Actualmente se recomienda una vacunación anual en zonas de riesgo como áreas de parques y algunas zonas de Lima consideradas de alto riesgo. Se colocan como primo vacunación un mínimo de dos dosis, con intervalos de cuatro semanas.

\section{Vacunas no esenciales u opcionales}

Las vacunas opcionales no son esenciales debido a que su efectividad es muy variable, debido principalmente, a que ciertas cepas infecciosas mutan constantemente modificando su capacidad antigénica. Así mismo, los cuadros clínicos que producen estos microorganismos son leves e incluso los animales pueden recuperarse sin tratamiento o con alguna terapia de soporte. Por lo tanto, las vacunas opcionales pueden ser utilizadas de acuerdo con el criterio del médico veterinario, según las características que adoptan las enfermedades y teniendo en cuenta las condiciones sanitarias y de inmunización del área donde se encuentra la práctica veterinaria. En Perú dichas vacunas son:
- Bordetella. La duración de la inmunidad no ha sido demostrada científicamente para su aplicación parenteral.

- Parainfluenza, Virus Parainfluenza Canina (VPiC). La vacuna disponible en el país para aplicación parenteral no provee un nivel de protección suficiente si se compara con la forma intranasal.

- Coronavirus

\section{Vacunas cuya eficacia no ha sido demos-} trada y cuyo uso no se recomienda

- Microsporum canis (dermatofitosis)

- Giardia

\section{Vacunaciones en Felinos}

En el Perú no se cuenta con una guía que indique las vacunas recomendadas en los felinos domésticos. Diversas asociaciones a nivel internacional han sustentado recomendaciones de vacunación; entre estas la American Association of Feline Practitioners (AAFP), la WSAVA y la European Advisory Board on Cat Diseases (EABCD). Estas instituciones dan pautas relacionadas a cada vacuna, y si deben o no ser aplicadas a los gatos dependiendo de la edad y estilo de vida; sin embargo, estas guías no son aplicables a la realidad peruana, de allí la importancia de establecer criterios médicos locales sobre la vacunación de esta especie.

Los protocolos de vacunación deben ser elegidos con base al riesgo de exposición al patógeno específico de cada individuo. Se deben tomar en consideración factores que puedan afectar la respuesta inmune de la vacuna como deficiencias nutricionales, inmunodeficiencias, enfermedades concurrentes o administración de medicamentos. Adicionalmente, ciertos individuos pueden necesitar un control vacunal mucho más estricto (más dosis o más frecuentes), dependiendo del estilo de vida; por ejemplo, en ga- 
tos con acceso a exteriores o si viven en un albergue o criadero en donde el tránsito de animales puede ser alto. Estos gatos tienen mayor riesgo de exposición a los agentes patógenos; por lo tanto, mayor riesgo de enfermar. En un gato de interior, que no sale a la calle (solo para las visitas al veterinario) y que no entra en contacto con otros gatos, la vacuna podría espaciarse o evitarse (según sea el tipo de vacuna), ya que estos gatos tienen un bajo riesgo a enfermar. Es por ello que toda vacuna debe ser aplicada por un Médico Veterinario colegiado y hábil, previa evaluación clínica y, de los antecedentes del paciente.

A nivel mundial, en medicina felina, se recomienda el uso de vacunas sin adyuvante debido al riesgo que tienen de producir reacciones pos-inoculación (principalmente el sarcoma pos-vacunal).

\section{Vacunas esenciales}

Las vacunas consideradas como esenciales que rutinariamente se usan en el Perú en gatos son las siguientes:

- Vacuna contra la panleucopenia felina, enfermedad causada por el Parvovirus felino (PVF) Vacuna contra la rinotraqueítis o herpesvirus felino (HVF-1)

- Vacuna contra el calicivirus felino (CVF)

- Vacuna contra la rabia. Esta vacuna debe ser aplicada anualmente por ley en todos los felinos

Se cree que el PVF tiene una prevalencia baja en zonas urbanizadas, pero puede ser alta en situaciones de hacinamiento y poca higiene. Produce una destrucción de las vellosidades intestinales y destrucción de las células hematopoyéticas, pudiendo ser mortal.

El CVF y el HVF-1 son los principales causantes del complejo respiratorio felino, enfermedad que en adultos produce una alta morbilidad, pudiendo ser fatal en cachorros no tratados o inmunosuprimidos. Los signos clínicos van desde conjuntivitis, úlceras corneales, sinusitis y secreciones oftálmicas y nasales causadas por el HVF-1 hasta lesiones bucales, úlceras y gingivitis causadas por el CVF.

El rol de vacunaciones recomendado para gatos en el Perú se muestra en el Cuadro 3.

\section{Vacunas no esenciales u opcionales}

Dentro de este grupo se encuentran vacunas que deben ser administradas únicamente a gatos que estén en riesgo real de exposición a los microrganismos causales. En ese grupo se tiene:

- Leucemia viral felina (VLeF). Es una vacuna que, a pesar de ser no esencial, es importante poder tenerla a disposición. Se aplica únicamente a gatos que ya fueron negativos al examen de laboratorio a la enfermedad y con real riesgo de contagio (acceso a exteriores o contacto con gatos positivos a la enfermedad). Se pone una dosis a $\operatorname{los} 8$ y 12 semanas con una revacunación al primer año. Luego, cada dos años si existe riesgo de contagio.

\section{Vacunas cuya eficacia no ha sido demos- trada y cuyo uso no se recomienda}

- Inmunodeficiencia viral felina (VIF). Vacuna que prácticamente ha dejado de ser utilizada a nivel mundial debido a que las pruebas diagnósticas detectan anticuerpos, tanto en animales enfermos como en animales vacunados. Es preferible evitarla para no generar falsos positivos.

- Peritonitis infecciosa felina (PIF) o Coronavirus felino (CoVF). Estas vacunas no han demostrado su efectividad en las pruebas de campo y, debido a esto, su producción es casi nula.

- Chlamydophila felis. No disponibles en el Perú. Su aplicación se recomienda solo en casos de real riesgo de exposición.

- Microsporum canis (dermatofitosis). Única disponible en el Perú; sin embargo, no se ha comprobado su real efectividad.

- Bordetella bronchiseptica

- Giardia. No se recomienda su uso por las mismas razones descritas para PIF. 
Cuadro 3. Rol de vacunación recomendado en gatos

\begin{tabular}{|c|c|c|c|c|c|}
\hline Vacuna & & Tipo $^{1}$ & Edad & $1^{\text {er }}$ refuerzo & Posteriormente \\
\hline \multirow[t]{2}{*}{ Esenciales } & $\begin{array}{l}\text { Triple } \\
\text { felina: } \\
\text { (PVF + } \\
\text { HVF-1 + } \\
\text { CVF) }\end{array}$ & VVM & $\begin{array}{l}8,12 \text { y } 16 \\
\text { semanas }\end{array}$ & $\mathrm{Al}$ año & $\begin{array}{l}\text { Cada } 3 \text { años. } \\
\text { Repetir anualmente } \\
\text { en casos de alto } \\
\text { riesgo }(*)\end{array}$ \\
\hline & Rabia & $\mathrm{VM}$ & $\begin{array}{l}\text { A partir de } \\
16 \text { semanas }\end{array}$ & $\begin{array}{l}\text { Al año } \\
\text { (obligatoria) }\end{array}$ & $\begin{array}{l}\text { Anualmente } \\
\text { (obligatoria) }\end{array}$ \\
\hline No esencial & VLeF & $\mathrm{Vr}$ & $\begin{array}{l}8 \text { y } 12 \\
\text { semanas }\end{array}$ & $\mathrm{Al}$ año & $\begin{array}{l}\text { Cada } 2 \text { años. } \\
\text { Repetir anualmente } \\
\text { en casos de alto } \\
\text { riesgo }(*)\end{array}$ \\
\hline
\end{tabular}

$\left.{ }^{*}\right)$ Alto riesgo y/o condiciones estresantes: animales con acceso a exteriores, que viven en albergues o criaderos. En estos casos se debe evaluar el flujo de ingreso de animales, para según eso definir el real riesgo de exposición a los antígenos. En gatos que no tienen acceso a exteriores, el médico veterinario debe evaluar la necesidad de la vacunación anual vs. el posible riesgo de una reacción pos-inoculación o reacción adversa a la vacuna

${ }^{1}$ VVM: virus vivo modificado; VM: virus muerto; $\mathrm{Vr}$ : virus recombinante

\section{Lugar de vacunación}

Se reconoce que el gato tiene una respuesta inflamatoria diferente y única que, dependiendo de los individuos, puede llevar a cambios cito-histológicos en el lugar de inoculación de cualquier producto o medicamento. Estos cambios pueden evolucionar de la siguiente manera:

- Inflamación y paniculitis

- Necrosis

- Granulación(PMN)

- Cambios neoplásicos (posible fibrosarcoma)

Es importante estandarizar el sitio de vacunación en el gato para identificar los antígenos que podrían causar reacciones locales y fibrosarcoma asociado. La AAFP y la Academy of Feline Medicine (AFM) han establecido pautas generales para la administración de las vacunas:
1. Los médicos veterinarios deben estandarizar los protocolos de vacunación dentro de su práctica y documentar la localización de las vacunaciones, el tipo de vacuna administrada y el fabricante en el registro del paciente.

2. Los siguientes son los sitios anatómicos de vacunación recomendados:

- Las vacunas que contengan antígenos de PVF, HVF-1 y CVF deben ser administradas en la región del hombro derecho.

- Las vacunas que contengan antígeno de la leucemia felina (+/- otros antígenos) deben ser administradas en la región izquierda caudal (miembro posterior izquierdo). Relacionando las iniciales de izquierda en inglés (Left) con la inicial de Leucemia.

- Las vacunas que contengan antígeno rábico (+/- otros antígenos) deben ser administradas en la región derecha caudal (miembro posterior derecho). Relacionando las iniciales de derecha en inglés (Right) con la inicial de Rabia. 
Eventos Adversos Relacionados

\section{A la Vacunación}

La administración de vacunas a perros y gatos es un trabajo rutinario en la clínica de animales de compañía. No obstante, al estar constituidas las vacunas por microorganismos patógenos, inactivados o no, y ser inoculadas en el paciente, existe un riesgo permanente de presentación de efectos no esperados como consecuencia de dicho procedimiento. Los eventos adversos son definidos como efectos colaterales o consecuencias inesperadas asociadas a la vacunación. Estos podrían ser causados por el antígeno, el adyuvante vacunal, las proteínas séricas o celulares o una combinación de los componentes de la vacuna.

Los eventos adversos observados con mayor frecuencia son:

\section{Dolor en el lugar de vacunación}

Se asume que este efecto está asociado a la reacción inflamatoria localizada en el punto de inoculación, el cual puede ser más notorio en animales jóvenes y de razas pequeñas. El dolor en el momento de la vacunación puede estar asociado al lugar de aplicación de la vacuna, empleo de una aguja de calibre demasiado pequeño, y al $\mathrm{pH}$ o temperatura de la vacuna, entre otros factores.

\section{Formación de nódulos benignos}

La tumefacción en el punto de inoculación de la vacuna puede estar relacionada ala reacción inflamatoria local como consecuencia de la estimulación inmunológica del animal vacunado, pero también puede estar relacionada a reacciones de hipersensibilidad. Los granulomas en el punto de inoculación están asociados con frecuencia a los adyuvantes vacunales, suelen ser estériles, no dolorosos y se resuelven en semanas a meses.

\section{Formación de abscesos}

La formación de abscesos en el punto de inoculación de la vacuna puede ocurrir como consecuencia de una contaminación de la vacuna empleada o una contaminación introducida en el momento de la vacunación.

\section{Sarcomas}

Los sarcomas asociados a la vacunación constituyen complicaciones graves y se observan como una tumefacción firme en/o cerca del lugar de la inoculación de una vacuna. Sin tenerse datos exactos se estima una incidencia de 1 caso por cada 10000 gatos vacunados, aunque el riesgo aumenta a medida que el gato recibe más vacunas. La causa de estos tumores de difícil tratamiento no está aún bien definida, pero se consideran como factores predisponentes a la inflamación local asociada al uso de vacunas adyuvadas y a vacunas a baja temperatura, e incluso hay estudios que sugieren una predisposición genética. La formación de un nódulo en el lugar de inoculación de una vacuna en gatos debe monitorearse, prestándose especial atención a su persistencia, tamaño y crecimiento; debiendo realizarse un examen histopatológico frente a la menor sospecha de malignidad.

\section{Reacciones sistémicas inespecificas}

Algunos pacientes vacunados pueden presentar signos inespecíficos como decaimiento, dolor, fiebre y anorexia pocas horas después de la vacunación. Se asume que estos signos serían consecuencias de la respuesta inmune del paciente frente a la inoculación de la vacuna, aunque también pueden deberse a la exposición a endotoxinas o sensibilidad a algún componente de la vacuna en particular. Estas reacciones pueden persistir por más de un día y con frecuencia no requieren de tratamiento.

\section{Reacciones de hipersensibilidad de tipo I}

La hipersensibilidad de tipo I es una respuesta inmunitaria excesiva a ciertos antígenos, generando lesión tisular y altera- 
ciones en el organismo. Estas reacciones están mediadas por altos niveles de inmunoglobulina $\mathrm{E}$ secretadas por los linfocitos B, como parte de una secuencia iniciada por la exposición a la vacuna. La severidad de estas reacciones va desde erupciones leves en la piel y edemas hasta signos respiratorios y cardiovasculares que pueden amenazar la vida del animal. Si bien estas reacciones son poco comunes, es importante tratar inmediatamente al paciente alérgico, realizar un monitoreo del paciente hasta por 48 horas después de la reacción y anotar el evento en su registro para tomar medidas preventivas adecuadas en sus siguientes vacunaciones.

\section{Inmunosupresión}

Se menciona que las vacunas de distemper canino a VVM cuando se combinan con Adenovirus canino tipo $1 \mathrm{o} 2$, pueden generar una inmunosupresión en el paciente vacunado. Esta inmunosupresión puede iniciarse tres días después de la vacunación y persistir por 7 a 10 días. Las vacunas de distemper canino recombinante no causan este efecto.

\section{Falta de eficacia de la vacuna}

Como ninguna vacuna puede asegurar un $100 \%$ de eficacia, cabría esperar eventualmente casos de falla en la protección proporcionada. Conviene resaltar, no obstante, que muchos casos de aparente falla de protección podrían deberse a factores ajenos a la vacuna, como la vacunación de animales enfermos, expuestos o inmunosuprimidos, protocolos inadecuados o incompletos de vacunación, así como deficiencias en la conservación y administración de la vacuna. Es importante evaluar cada caso minuciosamente a fin de determinar si la falta de eficacia es o no real.

Se recomienda que los médicos veterinarios consideren el riesgo/beneficio de vacunar a sus pacientes caninos y felinos con cada antígeno, tomando en cuenta la situación de cada paciente en particular (riesgo de exposición al patógeno en cuestión, estilo de vida, contacto con otros animales, etc.). Al mismo tiempo, los clínicos veterinarios deben brindar a los propietarios toda la información concerniente a los riesgos de eventos adversos, a fin de que estos puedan detectarlos prontamente en caso de ocurrir y buscar asistencia médica inmediata, minimizando la incidencia de fatalidades y sus implicancias legales. También se sugiere mantener un periodo de observación después de la vacunación, a fin de detectar en la consulta posibles eventos adversos inmediatos y tratarlos con prontitud.

Los eventos adversos deberían reportarse a la firma productora de la vacuna a fin de poder cuantificar la incidencia de estas reacciones, determinar factores de riesgo, y en última instancia detectar lotes de vacuna que presenten una mayor incidencia y así tomar las medidas necesarias para evitar mayores incidentes. En el Perú no existe un programa oficial de farmacovigilancia que aglutine los reportes de todos los eventos adversos generados por las vacunaciones en perros y gatos, por lo que estos reportes deberían realizarse al menos a los fabricantes de los biológicos involucrados.

\section{Conclusiones}

La vacunación de perros y gatos es una práctica médica ejercida, única y exclusivamente, por un Médico Veterinario colegiado y hábil en todo el territorio nacional.

El profesional médico veterinario debe realizar el procedimiento de vacunación sustentado en el estado de salud de la mascota y en los fundamentos del uso de las vacunas como antígenos inocuos y eficaces para inducir una respuesta inmunológica protectora en las mascotas. Las vacunas empleadas deben ser capaces de proteger contra las infeccio- 
nes prevalentes en las áreas geográficas de distribución de caninos y felinos, bajo la premisa de riesgo/beneficio.

El médico veterinario aplica las vacunas en pro de la salud y bienestar animal y bajo el precepto de una atención médica informada al propietario y a la sociedad en general.

COLAVAC-Perú espera que estas guías de vacunación sirvan al médico veterinario peruano para estandarizar un rol de vacunación en mascotas de acuerdo con las necesidades individuales del paciente; siendo imperativo llevar registros de cada paciente y tomar en consideración las recomendaciones del lugar de inoculación, en especial en gatos, para así contribuir al estudio de la incidencia del sarcoma pos-vacunal.

\section{ReFERENCIAS}

\section{Blanco M, Gibello A, Cutulí M, Gómez} M, Domínguez G, Doménech A, Orden J, et al. 2013. Manual gráfico de inmunología y enfermedades infecciosas del perro y el gato. Zaragoza: Grupo Asís Biomédica. $116 \mathrm{p}$.

2. Day MJ, Schultz RD. 2014. Veterinary immunology: principles and practice. $2^{\text {nd }}$ ed. Boca Raton, USA: CRC Press. 317 p.

3. Day MJ, Horzinek MC, Schultz RD, Squires $R A$. 2016. WSAVA guidelines for the vaccination of dogs and cats. $\mathrm{J}$ Small Anim Pract 57: E1- E45. doi: 10.1111/jsap.2_12431
4. Ford R. 2004. Vacunas y vacunaciones. Buenos Aires: Inter-Médica. 142 p.

5. Hosie MJ, Addie DD, BoucrautBaralon C, Egberink H, Frymus T, Gruffydd-Jones T, Hartmann K, et al. 2015. Matrix vaccination guidelines: 2015 ABCD recommendations for indoor/outdoor cats, rescue shelter cats and breeding catteries. J Feline Med Surg 17: 583-587. doi: 10.1177/1098612X15590732

6. [INS] Instituto Nacional de Salud. 2007. Norma técnica de salud para la prevención y control de la rabia humana en el Perú. NTS No. 052-MINSA/ DGSP-V.01 R.M.981-2006/MINSA. Lima: INS. 137 p.

7. Iturbe T, Aguilar J, Basurto F, Guerrero J, Autrán de Morais H. 2017. Guías de vacunación para perros y gatos. COLAVAC-FIAVAC-México Parte I. Vanguardia Vet 15: 14-40.

8. Labarthe $N$, Merlo A, Mendes de Almeida F, Costa R, Dias J, Autran de Morais H, Guerrero J. 2016. COLAVAC/FIAVAC - Estrategias para vacinação de animais de companhia: cães e gatos. Clin Veterinaria 21: 114-120.

9. Scherk M, Ford R, Gaskell $R$, Hartmann K, Hurley K, Lappin M, Levy J, et al. 2013. 2013 AAFP Feline Vaccination Advisory Panel Report. J Feline Med Surg 15: 785-808.

10. Wellborn LV, DeVries JG, Ford R, Franklin RT, Hurley KF, McClure KD, Paul MA, et al. 2011. 2011 AAHA canine vaccination guidelines. J Am Anim Hosp Assoc 47: 1-42. 